\section{La música en el mundo de la animación}

\author{
Paloma Yébenes
}

Después del silencio, lo que más se acerca a expresar lo inexpresable es la música; o dicho de otra manera, la música empieza donde acaba el lenguaje.

Aldous Huxley a animación y la música han sufrido generalmente un alto grado de olvido por parte de muchos, representando ambas manifestaciones un papel en nuestra sociedad como artes infravaloradas y excluidas, y que normalmente incluimos en el amplio big bang del bobby personal, cuando algunos no encuentran la materia de estudio donde instalar dichas disciplinas. Sin embargo, estas "aficiones" para algunos inexpertos, sistemas de producción cultural, social, económico y artístico, para otros más hábiles, en definitiva, una profesión, son objetos de estudio y de investigación necesarios para la comunidad científica y evidentemente para el desarrollo óptimo de cualquier sociedad. Por ello, existe la necesidad urgente de unión de estos dos campos artísticos, recopilando una información dispersa y en muchos momentos ilusoria, que nos lleva a entender cómo se configura y estructura la banda sonora de una obra audiovisual animada. El conocimiento de estas dos artes, disciplinas profesionales y expresiones sociales en conjunto, se está viendo relegado a breves artículos, reseñas y bibliografía escasa, donde sus métodos y objetivos no quedan expuestos. 
La animación y la música fabricada para las obras de animación son parte de la amalgama de productos audiovisuales en su creación y difusión. Herramientas que configuran el sector de la producción audiovisual y en el caso de la música y de la banda sonora, instrumentos que pueden suponer un tanto por ciento muy elevado de éxito o fracaso de cualquier serie, largometraje o cortometraje, fundamentalmente si el destinatario es un target infantil. ${ }^{1}$

Las herramientas de trabajo en animación y los distintos elementos del proceso de creación de una obra varían según la técnica utilizada pero hay un componente común para aproximadamente el noventa por ciento de las animaciones: el elemento musical. Y se habla de un noventa por ciento, puesto que se otorga un margen del diez por ciento a las animaciones que no llevan ningún tipo de elemento sonoro, aunque por otro lado podemos afirmar que este pequeño porcentaje deriva en ciertas animaciones experimentales y normalmente dirigidas a un target adulto. La música en la animación para infantes se torna primordial como atrayente sensorial para este tipo de público, además de otras variables que quedan argumentadas en este proyecto de investigación, como bien pueden ser la identificación y la relación de una animación a través de la música y la banda sonora, tanto de cabeceras como de cierres de episodios, largometrajes o cualquier otro formato que permita el desarrollo de la animación. La música, por lo tanto, es uno de los elementos que ha supuesto y supone un punto de inflexión en el desarrollo de cualquier animación y que condiciona el resultado final de la imagen.

Es habitual encontrar en el sector del cine de animación la máxima que apunta, "existen tantas técnicas de animación como objetos existan". Dichos objetos se pueden manipular para producir en ellos movimiento. Pero acotando más aún esta definición y centrándola en el plan de trabajo de nuestros realizadores nacionales, podemos establecer una sucinta clasificación de procedimientos o técnicas de animación desarrolladas, comenzando con la más tratada hasta el momento, el dibujo animado, seguido de la animación de plastilina, muñecos articulados de madera -marionetas- y otros materiales, los recortables o collages, las composiciones trazadas

1 Las animaciones analizadas en el presente trabajo de investigación están exclusivamente destinadas a un target infantil, obviando las animaciones para público adulto, porque la televisión española no realiza compras de esta otra opción de animación de productos hechos en España, con excepción de alguna cinta en determinadas cadenas, pero siendo insuficientes para una amplia difusión. Con todo, a lo largo de este trabajo se han efectuado algunas referencias a series destinadas a un target adolescente o adulto. 
con arena de playa -usualmente de carácter poético- dibujos pintados, rayados y manipulados directamente sobre el celuloide o la película, la pixilación y animación de objetos, animación de personas, imagen real interactuada con dibujo animado, el fotomontaje, escaneado de personas, óleo sobre cristal, animación de sólidos, animación de verduras, hortalizas... hasta la animación por ordenador.

Hablamos de las técnicas y estas van acompañadas, indiscutiblemente, de un proceso de trabajo diferente en cada una de ellas. Las herramientas de trabajo varían según la técnica utilizada pero hay un componente común: el elemento musical.

La incorporación de la música a la imagen visual parte desde el mismo nacimiento del cinematógrafo que pretendía, entre otras causas, subsanar los primitivos y poderosos sonidos y ruidos emergentes de la máquina desarrollada por los Lumiere. ${ }^{2}$ Si entre sus razones prácticas y estéticas concebían este uso de la música, entre sus condiciones psicológicas y poéticas el trata- miento de la música concierne a la ambientación y a un estilo gratificante que hacía posible un mayor entendimiento narrativo, convirtiéndose en una buena costumbre en la primigenia del cine y justificada por la ausencia de la palabra hasta que Al Jonson emitió sus primeros mítines. El elemento musical, por lo tanto, ofrece un corpus a la imagen visual, un refuerzo que convenientemente utilizado puede dotarle de propia vida a una imagen. La música es parte de la universalidad del lenguaje cinematográfico.

En la imagen animada dichos conceptos van de la mano con la imagen de ficción. Algunos autores aseveran que la música en las películas de animación cobra más importancia que en los filmes de imagen real o de ficción, razón justificada por la responsabilidad de hacer más creíbles y verosímiles unos personajes no reales y que el espectador los identifica con lo irreal, algo que puede perjudicar la interpretación de la película. ${ }^{3}$ En la misma tesis, Gorka Cornejo afirma que: "la música opera de forma casi constante y

2 Muchos autores defienden que la imagen cinematográfica nace ligada a la música de forma natural por tradición, ya que todas las representaciones dramáticas, desde que estas existen, han ido acompañadas por ella. Teniendo en cuenta que un ritual religioso es una representación dramática con un contenido específico, no es exageración remontarse a la prehistoria. Avanzando en el tiempo encontramos las tragedias griegas, los dramas litúrgicos y misterios cristianos, Shakespeare, el teatro barroco, el melodrama con música del siglo XIX, el music hall (NIETO, José. Música para la imagen (La influencia secreta), 1996, p. 29).

3 "En un film animado la música posee una importancia mayor que en otro tipo de películas porque tiene la responsabilidad de hacer más creíbles y verosímiles unos personajes que por el hecho de no 
generalmente muy pegada a las imágenes, transcribiendo todos los matices visuales y emocionales que se dan cita en la pantalla, de forma que gran parte del éxito de las películas animadas depende de la adecuación de la música, de su poder evocador, así como de su fuerza y flexibilidad, ya que constituye un punto de apoyo constante y necesario para el espectador". No obstante, este último apunte constituye un punto de referencia subrayada y determinante, pero no más que en las películas de ficción. Entendemos que la música no tiene por qué adquirir más responsabilidad en una imagen animada que en una real, exactamente por el elemento connotador, es decir, lo que te sugiere, lo que la música puede arrastrarte a vivir y a sentir tus propias experiencias. Si ello lo interrelacionamos con el elemento denotador, es decir, lo que se manifiesta, podemos afirmar que la música está en la intención y en el logro y por ello la música como arte es intencional y ambas se pueden conseguir de la misma manera en una imagen animada que en una imagen de ficción. Si lo que nos provoca tal música es la suma de estos dos conceptos, no importa que una imagen esté confeccionada con fotogramas dibujados que con fotogramas fotografiados. Los códigos de la imagen animada sugieren un tipo y estilo de animación muy diferentes los unos de los otros. Nada tiene que ver un anime pionero de la estampa japonesa propio de Jiji Hanasaka, donde quedaba reflejado un estilo de dibujo realista (la mimesis como elemento de verosimilitud) reproduciéndose apariencias dibujadas con mucha minuciosidad, que un cartoon americano de los años cincuenta, como Gerald McBoing Boing de los ex Disneys, ${ }^{4}$ después dibujantes de la United Productions of America (UPA), dibujado también con esmero pero donde impera la caricatura y la exageración, y donde la figuración mimética no es tan exacta como en el caso opuesto. La música en ese sentido es un elemento equilibrista, de unión y transmisión de pareceres entre el espectador y la imagen.

Los músicos que realizan composiciones para las películas de animación tienen que saber conjugar las notas que componen con la acción de la ani-

ser reales, de carne y hueso, el espectador los identifica con lo irreal, algo que puede perjudicar la interpretación de la película". CORNEJO, Gorka. "La concepción musical y la animación", Animadrid 2003, 22 de diciembre de 2003. [en línea] <http://www.comohacercine.com/articulo.php?id_art=526\&id_cat=1>.

4 Muchos de los animadores de la Factoría Disney tuvieron que abandonar sus puestos de trabajo en dicha compañía, ya que en 1941 John Hubley, Dave Hilberman, Art Babbitt, entre otros muchos, fueron a la huelga en la que los animadores reivindicaban una mejora en sus contratos. Finalmente abandonaron la Disney y crearon la UPA, donde dibujaron personajes de reconocido prestigio y popularidad como Mr. Magoo. 
mación. Sin embargo, se nos abre una hipótesis de trabajo añadida a la principal o base: ¿supone la incorporación de la música en los productos de animación nacional en formato serie de televisión un punto de inflexión en el resultado final de la obra artística?, siendo la nueva: ¿se puede afirmar que la música para animación se hace más necesaria que para la ficción?

En respuesta a ello encontramos el término del sentido de la perfección, es decir, la concordancia perfecta entre el binomio dibujo-música que en las películas de imagen real no se puede conseguir de manera tan perfecta. El músico Carl Stalling, ${ }^{5}$ colaborador de War- ner con más de 600 bandas sonoras de dibujos animados y colaborador anteriormente de Walt Disney, de las primeras películas de Mickey Mouse, y Scott Bradley, ${ }^{6}$ compositor especializado en cortometrajes de animación, desarrollaron el revolucionario sistema del clic-track, que más tarde, Max Steiner, aplicaría al cine de imagen real. El clic-track es una técnica de medición destinada a obtener una perfecta sincronización entre imagen y música que consiste en marcar la película con una serie de perforaciones, de forma que al ser proyectada emita un chasquido homogéneo, según la pauta que desee el compositor. Con esto el director de

5 Carl Stalling imponía sus propias reglas de trabajo musical en la Compañía Disney, enfrentándose de manera directa con Walt Disney, ya que los efectos y sincronizaciones utilizados por Stalling se alejaban de las normas de la composición musical.

Como explica Giannalberto Bendazzi, ambos llegaron a un acuerdo: en las películas cómicas de Mickey, la música quedaría en un segundo plano, mientras que en la serie titulada Silly Symphonies dominaría sobre las imágenes que servirían como ilustración. The Skeleton Dance (La danza del esqueleto, 1929) fue la primera de estas "Sinfonías Tontas", una especie de danza macabra creada por Ub Iwerks para la música de Stalling, basada en la pieza de Eduard Grieg En la gruta del rey de la montaña, de su suite Peer Gynt. (BENDAZZI, Giannalberto. Cartoons, 110 años de cine de animación, 2003, p. 63).

Carl Stalling (1888-1974), que empezó en el mundo del cine en 1910 como pianista de una sala, ha sido uno de los visionarios de la música del siglo XX. Tras su periplo en la Disney, llega en 1936 a los estudios Warner Brothers, ocupando el cargo de director musical del Departamento de Animación hasta 1958, año en el que se retira. Fue el artífice de dar vida musical al Pato Lucas, Bugs Bunny o el cerdito Porky, entre otros muchos. Gran musicalizador de caricaturas, mezclaba de una forma magistral y con gran sentido del humor, su música propia con arreglos de melodías populares (entre las que destacan las de Raymond Scout) o de obras insignes de la música clásica. Él mismo se encargaba de incorporar los efectos sonoros a sus bandas musicales. Una de sus grandes aportaciones fue la expresión del movimiento que su música transmitía, pudiendo un oyente imaginárselo únicamente escuchándola, sin necesidad de tener que ver la imagen.

6 Scott Bradley (1891-1977) es el genial artífice de la música de los cortometrajes de Tom y Jerry. Audaz en sus planteamientos, impuso un estilo muy personal que influyó en posteriores músicos de animación. En su obra entiende el sonido musical como efecto sonoro y emplea un mickeymousing agresivo y caricaturizado como el propio cartoon, que salpica permanentemente una música inci- 
la orquesta dispone de una referencia rítmica constante que le permitirá dirigir la orquesta de forma sincronizada con las imágenes. Actualmente existen distintas técnicas para lograr la perfecta sincronización entre música e imagen, una de ellas es la creada por José Nieto. Las nuevas tecnologías permiten hacer de una manera fácil y cómoda cosas que hace unos años eran auténticas proezas técnicas, permitiendo en el mundo de la animación, en el cual el requisito de la sincronización resulta imprescindible, avances tremendos además de facilitar su trabajo al compositor y ahorrarle mucho tiempo.

Una segunda técnica musical propia del mundo de la animación que posteriormente se ha aplicado a todo tipo de películas, en especial las comedias, es la conocida como mickeymousing (su propio nombre indica la procedencia original de la técnica, derivado del ratón Mickey que Disney ideó y dio vida junto a Ub Iwerks) y que consiste en describir lo más detalladamente posible los movimientos y las acciones de los personajes, empleando la música como recurso onomatopéyico, es decir, intentar empastar la música y los efectos de sonido al movimiento.
Tanto en la imagen de ficción como en la imagen animada las pistas de sonido son iguales para ambos casos, existiendo tres pistas, una que lleva las voces, otra los efectos y la tercera la música, pero hay que observar la diferencia que se produce en su uso: en la animación siempre se utilizan en conjunto, a diferencia que en la ficción, en que se pueden concebir por separado.

Se ha dicho que: "los dos lenguajes universales sobre la tierra son la música y el silencio". A este pensamiento podríamos añadir que curiosamente los dos están incluidos en el cine. Dos lenguajes que aunque en este caso se conciben en función de la imagen, engrandecen y universalizan el séptimo arte. Más en concreto al cine de animación, porque si algún género o tipo de cine es más universal ese es el de la animación, que ni siquiera necesita de las palabras para transmitir ideas, sensaciones y situaciones, únicamente una historia, una imagen y la música son necesarias.

Música e imagen tienen mucho en común, fundamentalmente porque ambas transcurren en el tiempo. El movimiento se produce con arreglo a una serie de leyes comunes, como son

dental donde triunfa el jazz, el swing y la música estadounidense. Otras constantes son la incorporación del contratiempo, la apuesta por la disonancia y la serie dodecafónica para momentos y situaciones que se requieren, así como frases que finalizan sin resolución armónica, provocando que quede suspendido el discurso musical. 
las relaciones tensión-reposo, la dinámica y sobre todo la más directamente relacionada con el movimiento: el ritmo. $^{7}$

La música es un elemento más del producto audiovisual, aunque primordial. En animación cobra una importancia especial, se convierte en fundamental para la definición del producto. Es un personaje más, por su importancia a la hora de narrar historias. Dentro de los diversos formatos empleados en animación se ha seleccionado el de la serie animada infantil por desarrollar la banda musical unos aspectos y funciones muy concretos, a la par que amplios. No se puede olvidar que la música forma parte del propio ser humano, de un modo muy intrínseco, quizá es el arte más arraigado, además de invadir tantos estadios de la vida. Es posiblemente el arte que más se consume en el mundo: la radio, la televisión, el cine... se sirven de ella continuamente y no se conciben sin su colaboración. Se ha convertido en una compañera inseparable del hombre, desde su infancia hasta su vejez, en todas las circunstancias de su vida.

El niño se siente atraído y cercano a la música, convirtiéndose no solo en algo lúdico sino también en una perfecta y útil herramienta de aprendizaje, como reconocen las modernas líneas pedagógicas.

Sin embargo, y a pesar de su importancia y cercanía, la música es con frecuencia la gran olvidada del producto audiovisual. Pasa desapercibida, asumiendo su función secundaria a favor de la imagen. Durante muchos años, no se ha sabido apreciar su funcionalidad y sus recursos, tanto por parte de directores como por parte del público. Aun así, otros muchos han sido conscientes de su importancia. Ejemplificando esta posición encontramos opiniones tan contundentes como la del director Francis Ford Coppola: "El sonido es el mejor amigo del director porque influye en el espectador de manera secreta". ${ }^{8}$ Incluso dentro del mundo musical, la rama de composición al servicio de la imagen ha sido menospreciada ante la fuerza y tradición de la composición pura musical de la música de concierto. En España, esta realidad se incrementa y los compositores de audiovisual luchan por sobrevivir y por que su trabajo se aprecie en la medida en que merecen. Gracias al buen hacer de muchos de ellos esta situación cambia día tras día, y grandes compositores como José Nieto, Alberto Iglesias, Roque Baños y tantos otros que se sumarían a una lista onomástica destacada, consiguen

7 NIETO, José. Op. cit., p. 39.

8 Con esta frase abre su libro José Nieto (op. cit.). 
un puesto reconocido. La mayoría alterna otro tipo de composiciones y trabajos musicales con la composición cinematográfica y se muestran altamente polifacéticos, musicalmente hablando. Pero es que, además, la lista de músicos provenientes del mundo clásico con un trabajo reconocido en este ámbito, que han dedicado parte de su carrera compositiva al mundo del audiovisual y del cine en concreto, se hace igualmente extensa: Antón García Abril, Carmelo Bernaola, Luis de Pablo, Xavier Montsalvatge, Odón Alonso, Pedro Iturralde, Cristóbal Halffter...Y esto solo fijándonos en la historia del cine y la televisión más reciente, porque basta remontarse en el tiempo para que surjan nombres como Jacinto Guerrero, Durán Alemany, Ernesto Halffter, Gerardo Gombau, etcétera.

Este inconveniente del reconocimiento se acrecienta todavía más si cabe para la música en la animación, cuando sin embargo se efectúan obras de gran valía y belleza. Pretendemos así, en definitiva, descubrir o iniciar el camino para encontrar una obra musi- cal diferente pero plena y encontrar nombres y figuras importantes en la historia de la música de la animación. Sirva de ejemplo, haciendo uso de músicas conocidas internacionalmente, el caso de: ¿Quién teme al lobo feroz?, tema principal de la banda sonora de Los tres cerditos (Buró Gillett), del compositor Frank Churchill, ${ }^{9}$ una de las melodías más populares desde 1933.

\section{La música en el lenguaje cinematográfico}

No sería lógico realizar un estudio en el que la música constituyese como disciplina un pilar básico, sin abordar una aproximación a su definición. Decimos aproximación porque la respuesta a la pregunta qué es la música supone, por sí misma, un amplio objeto de estudio que no ha lugar en esta investigación, y de la que se han ocupado, con mayor o menor acierto, múltiples autores. Es complejo elaborar una definición lo suficientemente completa, que abarque la totalidad del fenómeno musical, y que nos permita discernir qué es música y qué no es música. ${ }^{10}$

9 A este gran compositor se deben, entre otras, las bandas sonoras de los clásicos de Disney, Blancanieves y los siete enanitos (1937) junto a Leight Harline, y Paul Smith y Dumbo (Ben Sharpsteen, 1941) junto a Oliver Wallace. Así como canciones memorables de Bambi (David D. Hand, 1942), como Love is a song, I bring you a song, entre otras, compuestas con la colaboración de Larry Morey, o Never smile at a cocodrile, de Peter Pan (Clyde Geronimi, Wilfred Jackson y Hamilton Luske, 1953). El score de Bambi es de Eduard H. Plumb y el Peter Pan de Oliver Wallace, quien también compuso las canciones.

10 Hoy se acepta que todo sonido puede ser música siempre y cuando posea un significado para alguien; cualquier sonido o incluso un ruido que produzca goce estético al oyente. A lo largo de la 
El concepto de música procede del término griego musikè (monsich), el cual se entendía el "arte de las musas", es decir poesía, danza y música como unidad. Más tarde se independizaron y cobraron vida y caminos independientes.

Partiendo de la definición básica de música como el "Arte de combinar los sonidos y silencios en el tiempo", se descubre que la música es un arte, además de una ciencia. ${ }^{11}$ Hay que añadir que es también un lenguaje, completando así su triple dimensión.

La música es un lenguaje universal de la cultura. Por esta razón, constituye desde el principio de la humanidad una de las manifestaciones más importantes dentro del contexto cultural de cualquier época o civilización.

Es la más universal de todas las manifestaciones culturales. Una de las

historia se han elaborado muchas y variadas acepciones de esta disciplina. Dependiendo de los autores y de los distintos periodos en que fueron emitidas estas definiciones podemos agruparlas según su carácter en:

-Definiciones metafísicas, parten de una concepción metafísica a priori, en vez de la observación de hechos musicales. Adjudican a la música una función importante, al poder expresarse con ella ideas, valores, esencias..., que no permite el lenguaje hablado ni los medios de razón lógica. Otorgan a la música una función ética. El padre de las teorías metafísicas de la música es Platón, aunque antes ya el pitagorismo recalcó una categoría parecida regida por la ley del número. La música participaba de la esencia misma del cosmos. Las leyes armónicas que regían la ciencia musical eran las mismas que las que regían la física.

-Definiciones formalistas, en las cuales el acento recae sobre la obra, sobre la materia musical básica (sonido y silencio). Fue Hanslinck, en la segunda mitad del siglo XIX, el más destacado formalista musical, considerando a esta como "formas móviles de sonido", y negándole toda capacidad de expresión de sentimientos. En una línea de pensamiento similar podemos situar al músico Igor Stravinsky.

-Definiciones psicológicas, subrayan el efecto que la música produce en nuestra sensibilidad, convirtiéndose en un lenguaje. Ejemplo de este tipo de definición es la de Descartes: "intérprete privilegiada de la vida emotiva y sentimental, para ello deberá imitar la naturaleza. Lenguaje del corazón". También podemos incluir las estéticas hedonistas y todas las que hacen hincapié en que la música conmueve y hace sentir algo a la persona.

-Definiciones mixtas, son las que reconocen el aspecto "formal" de la música, pero también defienden la idea de que influye en la vida afectiva del hombre. Así, el arte musical no es ni enteramente "objetivo" ni por completo "subjetivo". Modelo de esta última tipología es el representado por Kant, que reconoce la concepción formal de la música al tiempo que la capacita para animar el espíritu y provocar un agradable goce personal.

11 Que la música es arte, es aceptado actualmente con facilidad por la mayoría. Es el acto, la facultad mediante la cual el hombre, valiéndose del sonido y del silencio, imita o expresa lo material o inmaterial y crea. Por tanto, su objeto es manifestar la "belleza" por medio de los sonidos. Entendemos que cualquier manifestación artística, incluyendo la música, no ha de perseguir necesariamente la consecución de belleza para que sea considerado arte. Ejemplos encontramos muchísimos y quizá los más claros y llamativos en muchas corrientes y estilos de la música del siglo XX, que incluso 
afirmaciones más tajantes en este sentido la realizó Goethe cuando dijo: "Entre todas las cosas imaginables elegimos la música, porque de ella salen caminos bien trazados en todas las direcciones".

Es un lenguaje no verbal, difícil de traducir en conceptos y que se desarrolla en un campo eminentemente simbólico -muy parecido de este modo al lenguaje corporal o gestual, a la danza...-. Es un lenguaje no conceptualizable, nunca podremos asegurar que una música dice tal cosa, pero sí que sugiere, provoca, induce... Va más allá del lenguaje hablado o escrito, más allá de la conciencia, comunicando sensaciones y sentimientos que incluso en ocasiones no pueden transmitirse de otro modo y que llegan a lo más profundo, sin que nuestra volun- tad pueda intervenir la mayor parte de la veces.

En resumen, es un arte asemántico, ya que no puede decirnos nada de cuanto puede comunicarse mediante el lenguaje común. Por esto mismo, y en opinión de Fubini, la música se sitúa por encima de cualquier medio normal de comunicación. No tiene necesidad de expresar lo que el lenguaje común, ya que va más lejos al captar la realidad a un nivel mucho más profundo, captando la esencia misma del mundo, la idea, el espíritu, la infinitud. Mayor es el poder de la música cuanto más lejos se encuentre de la semanticidad y la conceptualidad. Como señaló Lévi Strauss, la "música es el único lenguaje que a un tiempo es inteligible pero intraducible. Es el misterio supremo de la ciencia del hombre".

incorporan el ruido, la disonancia, lo feo... como elementos estéticos. El término belleza es empleado por tanto con un sentido más amplio que el que se le otorga tradicionalmente.

Pero la música también es ciencia, ya que está formada por el conjunto de leyes que rigen la producción de los sonidos. Stokowky expresaba esta realidad afirmando: "podemos no ser conscientes de ello, pero al mismo tiempo, escondido en el fondo de la música, existe otro mundo complejo de ondas sonoras y de las relaciones matemáticas que las rigen". A lo largo de los siglos la música ha sido considerada ciencia por muchos pensadores y estudiosos. El primero en apuntar este concepto fue Pitágoras en el siglo VI a. C. Partidario de que la música se basaba en el número y, por tanto, en las leyes matemáticas, investigó el fundamento matemático de las relaciones entre los sonidos, otorgando así a este arte categoría científica y metafísica al mismo tiempo. Seguidores de su teoría musical y sus principios fueron San Agustín, Boecio, Casiodoro... y avanzando todavía más en el tiempo, teóricos musicales como Bartolomé Ramos de Pareja y músicos como Luís de Narváez (siglo XVI), Rameau (siglo XVIII), los sistemas racionalistas... No podemos olvidar que incluso durante la Edad Media, la música se estudiaba en las universidades dentro del Quadrivium medieval, junto con la geometría, la aritmética y la astronomía.

Ulrich Michels diferencia en la música dos elementos: el material acústico y la idea intelectual, que se combinan y forman una imagen unitaria. El material acústico es el vehículo del que se vale la idea intelectual, "la inspiración". Es decir, este experimenta una preparación premusical, se seleccionan los soni- 
Los materiales básicos, la materia prima de la música, son el sonido y el silencio. Sonido es básicamente todo agente físico que impresiona el sentido del oído. Aunque se emplea como un término genérico para designar cualquier experiencia sonora, en sentido estricto es toda sensación agradable producida por un movimiento vibratorio armónico. En oposición, ruido es el resultado de un movimiento vibratorio aperiódico e inarmónico. ${ }^{12}$ Son muchos los autores que denominan ruido, en animación, a los efectos especiales de sonido, que resultan básicos en el desarrollo de este arte.

El silencio es la ausencia de sensación acústica, lo que no quiere decir que no contenga en sí mismo una carga significativa, sino al contrario, es un elemento musical de primer orden cargado de contenido expresivo. Sus funciones como expresión sonora son múltiples, desde convertirse en pausa reflexiva que ayuda a valorar el mensaje, a ejercer intencionalidad dramática, reva- lorizar sonidos anteriores y posteriores, etcétera. José Nieto comenta que "uno de los efectos dramáticos más afectivos que la música puede producir es la valoración del silencio". 13

La música, elemento comunicador de primer orden, lenguaje de emociones que alcanza a veces donde las palabras no llegan, refuerza su contenido y poder junto con la imagen. La música unida a la imagen no es un fenómeno moderno exclusivo del cine. Su origen se remonta a la antigua tragedia griega como manifestación teatral, que combinaba el sonido con su correspondiente coreografía y argumento, convirtiendo a los cantantes también en actores. Esta unión de música y drama continuará su desarrollo desde entonces, dando lugar al nacimiento de géneros como la ópera y el musical.

Por tanto, la música puede ser complemento de otros lenguajes, como ocurre con el cine, la publicidad, la

dos entre los existentes y se ordenan en intervalos, sistemas tonales, escalas..., adquiriendo los sonidos de ese modo cualidades específicas. Destaca claramente en este ordenamiento su carácter científico, ya que se fundamenta en reglas y leyes. La idea intelectual es la que convierte este material acústico en arte.

12 Este tipo de clasificación basada en la agradabilidad sonora, aunque correcta deja paso a consideraciones subjetivas, ya que depende del tipo de sensación producida en el oyente para ser entendida como sonido o ruido. Científicamente se diferencia entre ruido blanco, aquel que contiene todas las frecuencias del espectro audible con la misma intensidad, y ruido rosa, el que contiene todas las frecuencias del espectro audible pero su intensidad decrece en cada octava. Con todo, no hay que olvidar que el ruido se convierte en elemento musical en determinados movimientos artístico-musicales, como sucede en muchas de las vanguardias del siglo XX.

13 NIETO, José. Op. cit., p. 43. 
televisión, la radio... Todos estos necesitan de ella. Deja de ser lenguaje en sí mismo para convertirse en elemento de otro lenguaje.

El gran valor de la música cuando es complemento de otros lenguajes es el de poder variar la capacidad comunicacional de cualquier imagen según sus características, es decir, según el tipo de música que se utilice. ${ }^{14}$

Es curiosa la paradoja que se extrae de una de las ideas de Theodor Adorno: ante la incredulidad del cine, la música, que es la más abstracta de las artes, favorece la credibilidad.

Desde las primeras proyecciones cinematográficas desarrolló su papel comunicativo y funcional, además de convertirse progresivamente, con el paso al cine sonoro, en un componente expresivo y estructural dentro del propio filme. De todos los elementos que configuran la película, es posiblemente la que establece una conexión más directa con el espectador. Solemos creer casi siempre más a la música que a la imagen. La música actúa de forma invisible y casi secreta, influyendo en el subconsciente del espectador, eligiendo por él de entre todo lo que ofrecen las imágenes aquello que considera esencial.

Siempre al servicio de la imagen, aunque en determinados momentos adquiera un grado de protagonismo importante, "la música de cine es aquella que todo el mundo oye, pero que nadie escucha", como sentenció Ennio Monricone. Escuchemos la música y descubriremos un nuevo mundo en el propio cine, potenciándose el contenido y la expresividad de imágenes, surgiendo nuevas sensibilidades y apreciaciones.

Música e imagen tienen en común que transcurren en el tiempo. El movimiento se produce con arreglo a una serie de leyes comunes, como son las relaciones tensión-reposo, la dinámica y, sobre todo, la más directamente relacionada con el movimiento: el ritmo. $^{15}$

Michael Chion nos remite a la opinión de Abel Gance, manifestada en una conferencia sobre cine, en la que al establecer una asimilación entre el carácter físico del sonido y el de la imagen sobre el modelo clásico de la falsa analogía, manifestaba: "Hay dos tipos de música: la música de los sonidos y la

14 Estilísticamente, la música en el cine y en general en los productos audiovisuales se caracteriza por su variedad y eclecticismo. Desde el sinfonismo romántico del siglo XIX, la música contemporánea, las vanguardias, la ópera o la música sacra, hasta la música popular, el folclore, el rock, el pop, el new age, la música electrónica o el jazz, todos son válidos, siempre y cuando el autor sepa por qué lo hace y por qué lo quiere de aquella manera.

15 NIETO, José. Op. cit., p. 49. 
música de la luz, que no es otra que el cine; y esta última es más alta en la escala de vibraciones que la primera". ${ }^{16}$

Todo lo referido a la música cinematográfica es perfectamente aplicable a la de la animación. Por animación entendemos la creación de una ilusión de movimiento a través de la unión de una secuencia de imágenes inmóviles. ${ }^{17}$ Basada en multitud de técnicas y procesos, la animación básicamente consiste en crear el movimiento. La música, entre otras muchas cosas, es también movimiento.

La música condiciona mucho al animador. Lo ideal sería que la música se grabara antes de efectuarse la animación, a diferencia de las películas de imagen real, donde la sincronización es posterior. Sin embargo, la realidad cotidiana impone que se grabe generalmente en posproducción, aunque en la mayoría de los casos las secuencias musicales -las canciones sobre todo-, que tienen dibujos muy precisos $y$ detallados para coordinarse con el sonido son grabadas preliminarmente. Con todo, el trabajo del músico debe comenzar en la preproducción de la obra.

Steamboat Willie (1928) no es solo el primer dibujo animado en el que comenzó sus primeras aventuras el famoso ratón Mickey Mouse, sino que además es el primer dibujo animado con sonido sincronizado. La música de este cortometraje demuestra la importancia que Walt Disney concedía en sus producciones al elemento musical y que más adelante se confirmó en sus Sinfonías tontas. En Steamboat Willie, Disney trabajó grabando la música después del dibujo, tras el duro trabajo de sincronización realizado con la imagen, ideó para posteriores trabajos grabar primero la música y animar a los personajes a partir de ella, inaugurando una técnica que fue seguida por muchos autores.

En este sentido, Francis Chagin realiza un paralelismo con la danza para explicar la importancia de la música de animación: "El ballet -como las películas de animación- emplea la música como base del movimiento. Por tanto la partitura debe escribirse de una forma definitiva antes de que el coreógrafo o animador puedan efectuar su contribución". ${ }^{18}$

Chion explica que si la animación parte de una música o de diálogos pregrabados, sobre los que hay que sincronizar movimientos precisos, se dispone de una especie de partitura guía sobre la que están indicados, con cronometrajes

16 CHION, Michel. La música en el cine, 1997, p. 294.

17 TAYLOR, Richard. Enciclopedia de técnicas de animación, 2000, p. 7.

18 Citado en RADIGALES, Jaume. "Creació i muntatge musical en el dibuix animat clàssic". Tripodos 11, p. 113. 
precisos, la música, los ruidos y los diálogos, que sirve de base al animador. ${ }^{19}$

En el formato de serie televisiva que nos ocupa, muchos son los compositores que antes de iniciar su trabajo acostumbran a visionar con el director el episodio, para acordar, entre otros aspectos, el papel que desempeñará la música en el discurso narrativo, los puntos de entrada y el cariz que debe tener la música. Es decir, dar respuesta a las tradicionales preguntas: ¿para qué la música?, ¿dónde va a ir la música?, ¿cuándo debe empezar y terminar la música?, y ¿cómo debe ser la música? En este sentido, la complicidad con el director se hace imprescindible, la música es una parte más de ese compendio de formas artísticas al que se le llama "obra audiovisual".

La ventaja que aporta el hecho de que el músico aparezca en las últimas fases de producción del episodio es que tiene la facultad de subrayar lo mejor y lograr que lo mediocre pase inadvertido.
En realidad, el formato empleado en animación no implica planteamientos musicales diametralmente opuestos, aunque el tipo de metraje sí repercute tanto en el tiempo como en los medios, siendo estos capitales para las producciones de una banda sonora, ya sea largometraje, cortometraje o serie de televisión.

Una serie de televisión suele componerse de secuencias no extensas, lo cual implica que la música se adecue a estas, sin embargo, el tiempo de un largometraje puede resultar un lujo para el compositor en cuanto al desarrollo de ideas musicales. En otro orden, el largometraje suele optar en cuanto a su tímbrica por la utilización de un sonido sinfónico, con una orquestación amplia y variada, sin embargo, la música para series televisivas suele emplear pequeñas formaciones, más íntimas y familiares. ${ }^{20}$

Con todo, en animación el ritmo de la imagen está permanentemente sometido al ritmo sonoro, por eso es constante la fragmentación, multiplicándose los temas basados en célu-

19 CHION, Michel. El cine y sus oficios, 1986, pp. 436-437.

20 Chion explica que el modelo de formación pequeña empleada en las obras destinadas a la pantalla pequeña fue preconizada por el músico Darius Milhaud: maderas graves, como flauta y clarinete bajo, contrabajo y percusión (CHION, Michel. Op. cit., p. 400).

A lo largo de estas páginas observaremos que son muchos los autores que para acompañar las secuencias de las distintas series optan por agrupaciones instrumentales pequeñas, buscando la claridad y expresividad sonora, destacando los matices y connotaciones de los diferentes timbres y predominando, además de la cuerda frotada, los instrumentos de viento madera, así como la percusión, preservando los de viento metal para momentos concretos que requieran la brillantez de su presencia. 
las rítmicas o melódicas, los subrayados de la acción, la importancia del timbre, explotando su capacidad simbólica de representación cultural y antropológica, etcétera.

\section{La banda sonora: Elementos que la conforman}

La banda sonora para una obra de animación o de imagen real ${ }^{21}$ se basa en los diálogos -grabados en estudio o en directo, es decir, cuando se graba a la vez el sonido y la imagen, lo que conlleva riesgos de calidad en el resultado final-, los efectos de sala -sonorización de los ruidos que han de incorporarse a la animación-y, por último, en la música de ambientación, para reforzar la estética del dibujo.

La efectividad de cada uno de los componentes estará en relación directa con su capacidad de convivencia con los demás, especialmente con el diálogo, cuya inteligibilidad, objetivo prioritario de la mezcla final, condicionará la presencia de los otros. ${ }^{22}$

De acuerdo con esto, y tal como explica Josep Lluís i Falcó, se debe matizar la diferencia entre banda sono- ra y banda sonora musical. La amplitud del primer término incluye los elementos anteriormente mencionados, quedando únicamente la música como integrante de la banda sonora musical. $^{23}$ Coloquialmente se suele hablar de la banda sonora de un compositor, cuando habría que especificar que se refiere a la banda sonora musical, ya que en la creación de la banda sonora de una obra intervienen diferentes profesionales ajenos al mundo de la composición musical.

En animación los efectos especiales traspasan a menudo la frontera de la música, formando incluso parte de ella misma y orquestándose en completa sintonía y asociación. Actualmente, cada vez son más los músicos que invaden el campo de los efectos especiales, para controlar perfectamente la fusión de estos dos elementos de la banda sonora, para que ninguno de los dos entorpezcan, eclipsen o disminuyan la acción y función de cada uno. Conseguir un perfecto equilibrio de las tres pistas de la banda sonora, con la finalidad de no saturar sonoramente, es un objetivo de toda obra cinematográfica, pero en animación cobra -si cabe- una dimensión de mayor importancia.

21 En la banda sonora de una película de imagen real existen cuatro fuentes de sonido, además de la banda sonora musical y los efectos de sonido estarían la del sonido directo (tomado simultáneamente con las imágenes) y la del diálogo (doblaje de las voces, grabadas en estudio).

22 NIETO, José. Op. cit., p. 80.

23 FALCÓ, Josep Lluís I. "Método de análisis de la música cinematográfica”. D’Art 21, 1995. 
La música es un elemento expresivo y estructural de primer orden, convirtiéndose en una de las herramientas más importantes con las que cuenta el director para transmitir su discurso.

La música de ambientación o de acompañamiento puede desarrollarse de dos formas diferentes (también aplicable en la música de imagen real): a través de la música diegética y de la música no diegética. La diegética, llamada por diversos autores también accidental o source music, es la que se compone para una imagen donde aparece la referencia de emisión de los sonidos musicales. La que oyen los personajes en el desarrollo del metraje, y permite una perfecta ambientación. ${ }^{24}$ Sin embargo, en la no diegética, incidental o featured music, no tiene por qué aparecer la fuente sonora, es aquella que solo es escuchada por los espectadores, no por los personajes. ${ }^{25}$ El músico, en este aspecto, tiene mayor libertad de movimiento, porque no está condicionado directamente por la imagen.

José Nieto indica que existen tres procedimientos para la creación de una banda sonora: cuando la música es encargada en su totalidad a un compositor; cuando la banda sonora incluye única y exclusivamente música pregrabada; y, finalmente, cuando se emplean, en conjunto, las dos opciones anteriores. La elección de uno u otro procedimiento depende de varios factores, entre los que se pueden citar el criterio del director, las intenciones narrativas del argumento literario, las propuestas escénicas que tenga previsto llevar a cabo y la incidencia que la música deba representar en relación con ambos aspectos. $^{26}$

\section{Funciones de la música}

Muchos han sido los autores destacados que han catalogado las funciones que ejerce la banda sonora musical. Se pueden diferenciar entre funciones estructurales y funciones expresivas. Chion insiste en la capacidad funcional de la música, que puede incluso coestructurar: “... es decir, contribuye, junto con otros elementos, a acompasar la forma general por el lugar determinante de sus intervenciones". 27 Entre las funciones estructurales, y siguiendo los escritos de Nieto y Chion, podrían citarse:

- Aportar ritmo a la imagen o modificar la percepción del ritmo de esta.

24 VVAA. El legado musical del siglo XX, s.l: Enrique Banús, p. 152.

25 XALABARDER, Conrado. Enciclopedia de las bandas sonoras, 1997, pp. 28-29.

26 NIETO, José. Op. cit., p. 37.

27 CHION, Michel, Op. cit., p. 217. 
- Resaltar o no los cortes entre los planos, afectando la percepción del ritmo.

- Capacidad para influir sobre la continuidad de la narración.

- Provocar, clara y fácilmente, la sensación de continuidad y, mucho más fácilmente aún, la sensación de cambio o de ruptura.

Entre las funciones expresivas se pueden incluir, entre otras:

- Capacidad de transmitir todo tipo de conceptos, ideas y emociones, además dentro de una gama casi infinita de matices y gradaciones.

- Modificar sensiblemente, si no el contenido, sí el valor expresivo de una secuencia.

- Poner de relieve los distintos aspectos de la imagen, guiando el punto de vista del espectador.

- Subrayar y potenciar el contenido de las imágenes.

Conrado Xalabader, en su Enciclopedia de las bandas sonoras, las resume de la siguiente manera:

- Ambientar las épocas y lugares en que transcurre la acción.

- Acompañar imágenes y secuencias, haciéndolas más claras y accesibles.

- Sustituir diálogos innecesarios.
- Activar y dinamizar el ritmo, o hacerlo más lento.

- Definir personajes y estados de ánimo.

- Aportar información al espectador.

- Implicar emocionalmente al espectador.

El profesor Octavio José Sánchez compendia las funciones de la música en el cine que el musicólogo Russell Lack, en su estudio La música en el cine (1999), expone con gran sutileza:

- Acceder a nuestra experiencia del paso del tiempo.

- Dar cuenta no solo de la psicología de los personajes, sino también del tejido social de las comunidades culturales particulares.

- Focalizar el tiempo y el espacio.

- Sustentar la narrativa. Estructurar y enfocar la acción dramática.

- Poner una marca de familiaridad a entornos visualmente extraños o acentuar el extrañamiento.

- Impactar dramáticamente, incluso por ausencia.

- Desencadenar respuestas emocionales.

- Producir asociaciones.

- Acentuar el estilo básico de las escenas. 
- Trazar a gran escala el ambiente de una escena.

- Traducir o simplificar la complejidad del laberinto de las imágenes.

- Servir de eje en los saltos temporales.

Todas estas funciones, y muchas otras más, son aplicables al papel desarrollado por la música en las obras animadas. En el cine clásico de animación, comenta el profesor y crítico musical Jaume Radigales, cabe hablar de tres funciones posibles de la música: la verosimilitud, la diversión y el distanciamiento. ${ }^{28}$

En la animación, al igual que en el cine de imagen real, la música tiene encomendada su misión en el conjunto de la obra audiovisual. Pep Lladó, uno de los músicos que más ha compuesto en series de animación españo- la, reconoce que aquella música que es eficaz en su cometido es una buena música. A lo cual otro de los incondicionales de la música de series animadas nacionales, Josep Roig, añade: "Todo es infinito y por supuesto el arte también. Una imagen tiene millones de músicas. ¿Cuál es la mejor? Pues evidentemente, muchas, muchísimas, siempre y cuando contenga unos requisitos clave como la concordancia con el diseño, el lenguaje y el estilo del proyecto". ${ }^{29}$

El maestro Antonio Areta ${ }^{30}$ opina que una música buena en animación ha de tener calidad y belleza, además de los rasgos concretos que exige el proceso que mejor se adecue al tratamiento del filme: "La magia consiste en hacerse uno mismo parte de la historia y después lograr describirlo". 31

28 RADIGALES, Jaume. Op. cit., p. 109.

29 Entrevistas realizadas con los dos compositores para el desarrollo de este trabajo de investigación.

30 Antonio Areta es uno de los compositores más representativos del cine de animación español. Profesor de armonía del Real Conservatorio Superior de Música de Madrid durante más de treinta años, compaginó su actividad con la música cinematográfica en películas como Las gemelas (Antonio del Amo, 1963) o Al ponerse el sol (Mario Camus, 1967). Se dedicó durante muchos años al mundo de la animación, participando en casi todas las producciones de Cruz Delgado: los cortometrajes de Molécula (1966-1976), Mágica aventura (1974), El desván de la fantasía (1977), Don Quijote de la Mancha (1977-1981) y Los viajes de Gulliver (1983). Es el compositor de la inolvidable sinfonía protagonizada en TVE por la Familia Telerín, de los hermanos Moro, Vamos a la cama, con la que en los años sesenta esta familia invitaba a los más pequeños a irse a la cama. También participaron en ella los músicos Máximo Baratas y Modesto Rebollo.

31 YÉBENES, Pilar. Cruz Delgado: Una historia de animación en España. Córdoba: Filmoteca de Andalucía, 2005, pp. 166-170. 


\section{Bibliografía}

ADORnO, T. W. Sobre la música. Barcelona: Paidós, 2000.

ADORNO T. W. y H. EISLER. El cine y la música, 2. ${ }^{\text {a }}$ edición. Madrid: Editorial Fundamentos, 1981.

ALONSO, M., MATILLA, L. y M. VÁZQUEZ. Teleniños públicos/teleniños privados. Madrid: Ediciones de la Torre, 1995.

ARNHEIM, R. El cine como arte. Barcelona: Paidós, 1996.

A. S. "Pentagramas de película. Acordes y desacuerdos en el creciente mercado de la música de cine". Academia. Revista de Cine en España 29. Invierno del 2001.

BENDAZZI, G. 110 años de cine de animación. Madrid: Ocho y Medio, 2003.

BENET, Vicente J. La cultura del cine. Introducción a la bistoria y a la estética del cine. Barcelona: Paidós, 2004.

CÁMARA, S. El dibujo animado. Barcelona: Parragón Ediciones S.A., 2004.

CEBRIÁN HERREROS, M. Introducción al lenguaje de la televisión. Madrid: Pirámide, 1978.

CHION, M. La música en el cine. Barcelona: Paidós Ibérica S.A., 1997.
-. El cine y sus oficios. 2. ${ }^{\mathrm{a}}$ edición. Madrid: Cátedra (signo e imagen), 1986.

DELGADO, P. E. El cine de animación. Madrid: J. C. Ediciones, 2000.

DUCA, Lo. El dibujo animado. Buenos Aires: Ediciones Losange, 1957.

FALCÓ, J. L. I. "Método de análisis de la música cinematográfica". D'Art 21. Barcelona: Departamento de Historia del Arte de la Universidad de Barcelona, 1995.

FUBINI, E. La estética desde la Antigüedad hasta el siglo XX. Madrid: Alianza Editorial, 1999.

GARCÍA, R. La magia del dibujo animado. Madrid: Mario Ayuso Editor, 1995.

HALAS, John. La técnica de los dibujos animados. Barcelona: Omega, 1980.

KRACAUER, S. Teoría del cine. La redención de la realidad física. Barcelona: Paidós estética, 1989.

LÉVI-STRAUSS, C. Mirar, escuchar, leer. Madrid: Siruela, 1993.

LONDON, K. Film Music: a summary of the characteristics features of its history, aesthetics, technique; and possible developments. Londres: Faber \& Faber, 1946.

MALLORY, M. Hanna-Barbera Cartoons. Londres: Virgin Publishing Ldt., 1999. 
MANVELL, R., y J. HUNTLEY. The technique of the film music. Nueva York: Hastings House Publishers, 1957.

MANZANERA, M., Cine de animación en España: Largometrajes 19451985. Murcia: Secretariado de Publicaciones e Intercambio Científico, Cuadernos 45, Universidad de Murcia, 1992.

MOSCARDÓ GUILLÉN, J. El cine de animación en más de 100 largometrajes. Madrid: Alianza Editorial, 1997.

NIETO, J. Música para la imagen: La influencia secreta. Madrid: SGAE, 1996.

PADRÓN, J. "Música y lenguaje cinematográfico". Papel Musical 4. Revista de análisis, información y crítica. Octubre-diciembre de 1989.

RADIGALES, J. "Creació i muntatge musical en el dibuix animat clàssic". Tripodos 11. Barcelona, 2001.

SÁNCHEZ, O. J. Música e imagen. Taller de Producción Aplicada de la Carrera de Producción
Musical de la Universidad Nacional de San Luis, 2002.

TAYLOR, R. Enciclopedia de técnicas de animación. Barcelona: Acanto, 2000.

TÉLLEZ, E. "La composición musical al servicio de la imagen cinematográfica. El discurso musical como soporte del discurso cinematográfico". Eufonía. Didáctica de la música 4. Julio de 1996.

VIVAR, H. La imagen animada. Análisis de la forma y el contenido del dibujo animado. Madrid: Editorial de la Universidad Complutense de Madrid, 1986. Colección Tesis Doctorales núm. $257 / 88$.

VVAA. El legado musical del siglo XX. s.1: Enrique Banús.

VVAA. Historia general del cine. La transición del mundo al sonoro. Vol. VI. Madrid: Cátedra, 1995.

XALABARDER, C. Enciclopedia de las bandas sonoras. Barcelona: Ediciones B. S. A., 1997.

YÉBENES CORTÉS, P. Cine de animación en España. Barcelona: Ariel, 2002. 


\section{Páginas web}

http://www.animacor.com http://www.animadrid.com http://www.animatoon.com http://www.audiovisualcat.net http://www.bsospirit.com http://www.cartoon-media.be http://www.cinevideo20.es http://www.cineytele.com http://www.comohacercine.com

http://www.dibunet.com

http://www.edimicros.es

http://www.egeda.es

http://www.electroweb.com

http://www.emueducacionmusical.com.ar

http://www.epdlp.com

http://www.fapae.es 